\title{
Fatigue Analysis of Engine Connecting Rod Based on Workbench
}

\author{
Dan Yang ${ }^{1,2}$, Zhen $\mathrm{Yu}^{1,2}$, Wentao Cheng ${ }^{1, \mathrm{a}^{*}}$ and Leilei Zhang ${ }^{2}$ \\ ${ }^{1}$ Key Laboratory of Metallurgical Equipment and Control Technology, Ministry of Education, Wuhan \\ University of Science and Technology, Wuhan 430081, China. \\ ${ }^{2}$ Hubei Key Laboratory of Mechanical Transmission and Manufacturing Engineering, Wuhan \\ University of Science and Technology, Wuhan 430081, China. \\ a154072471@qq.com \\ * please mark the corresponding author with an asterisk
}

Keywords: Engine connecting rod; Static analysis; Fatigue analysis

\begin{abstract}
The connecting rods are subjected to complex loads during engine operation. The load and boundary conditions of the connecting rod are obtained by kinematics and kinetic analysis, and the finite element model is established. In this paper, the connecting rod is analyzed statistically and the weak position of the connecting rod is determined. Then, under constant amplitude loading and cyclic loading of two different loads, the fatigue life and safety factors of the connecting rod are analyzed, to predict the fatigue life of the connecting rod and provide effective guidance for the future design of the connecting rod.
\end{abstract}

\section{Introduction}

The crank link mechanism is the core mechanism of the energy conversion in the reciprocating piston engine, and is responsible for the task of converting the reciprocating motion of the piston into the rotary motion of the crankshaft to output the torque. In the engine work process, the crank link mechanism is very complex, such as cyclical changes in the gas pressure, piston and connecting rod reciprocating inertia force and the crankshaft rotation centrifugal force [1]. With the continuous improvement of the power density of the modern engine, the working conditions of the crank link mechanism are harsher. Therefore, the strength checking and fatigue life calculation of the moving parts have become the core steps of the engine reliability design and testing [2].

Application of numerical method to predict fatigue life is an effective method to improve the design of engine parts. Ansys software is a kind of analysis software commonly used in the field of mechanical structure. Compared with the traditional analysis software, the simulation environment based on Workbench is more flexible and convenient, and it is widely used in fatigue analysis of mechanical parts. In this paper, fatigue life analysis of engine connecting rod is used to predict the life of connecting rod, which will guide the design of engine connecting rod in the future.

\section{Fatigue Analysis Theories}

The S-N curve shows the curve of the relationship between the fatigue strength and the fatigue life of a standard specimen under a certain cyclic characteristic, also referred to as the stress-life curve. [3]. As the basic data for fatigue calculation analysis, the $\mathrm{S}-\mathrm{N}$ curve of the material is indispensable. In this paper, the connecting rod is made of structural steel with elastic modulus of $2.0 \times 10^{11}$, Poisson's ratio of 0.3 , Density of $7850 \mathrm{~kg} / \mathrm{m}^{3}$ and Yield strength of $250 \mathrm{MPa}$. The S-N curve of this material is shown in Fig. 1. 


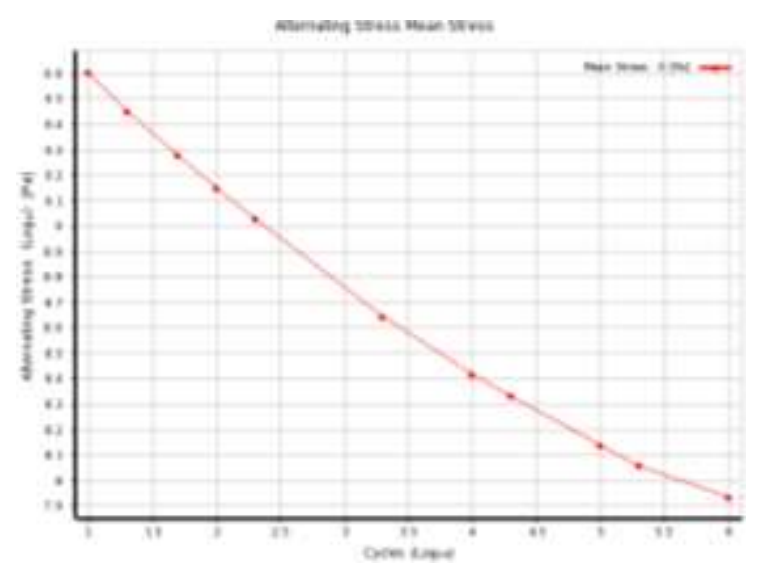

Figure 1. Finite S-N curve of structural steel

\section{Fatigue Analysis Process}

Finite Element Model Establishment. This article through the Solidworks to complete the establishment of three-dimensional model, the model saved as *. X_T file into the Workbench. After the grid is divided into the connecting rod, the finite element analysis model of the engine connecting rod shown in Fig. 2 is obtained.

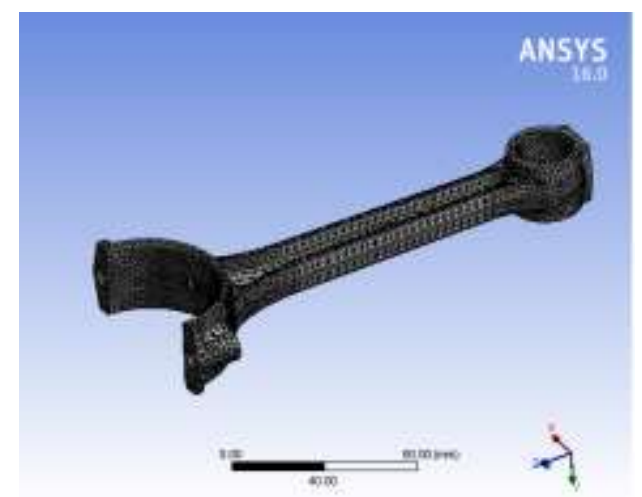

Figure 2. Finite element analysis model of the engine connecting rod

Load Boundary Conditions and Loads. In order to limit the displacement and rotation of the rigid body, the bolt holes and the small end of the li at both ends of the connecting rod are fully restrained. In other words, the piston pin hole (i.e. the inner surface of the small circle) is completely fixed, and a cylindrical constraint is applied on the inner surface of the two sides of the large semicircle, and the radial direction is fixed, and the circumferential and axial freedom [4]. The amount of deformation obtained by the final calculation refers to the deformation with respect to the fixed confinement plane. In this paper, the connecting rod is applied in two ways. One is to apply a constant amplitude load of $4500 \mathrm{~N}$ on the surface of the big semicircle of the connecting rod of the engine, and the second is to apply an arbitrary load of $4500 \mathrm{~N}$. The subsequent fatigue analysis can enlarge the force and obtain the fatigue analysis results, as is show in Fig. 3.

Statics Analysis Results. Before analyzing the fatigue of the engine connecting rod, the static analysis of the connecting rod must be carried out, that is, the distribution of the equivalent stress of the engine connecting rod. As shown in Fig. 4, the maximum stress (high stress zone) occurs at the transition of the small end of the connecting rod and the connecting rod shaft, the maximum stress is $56.624 \mathrm{MPa}$, which is less than the yield strength of the material itself. Therefore, the material is considered from the static strength is safe. 


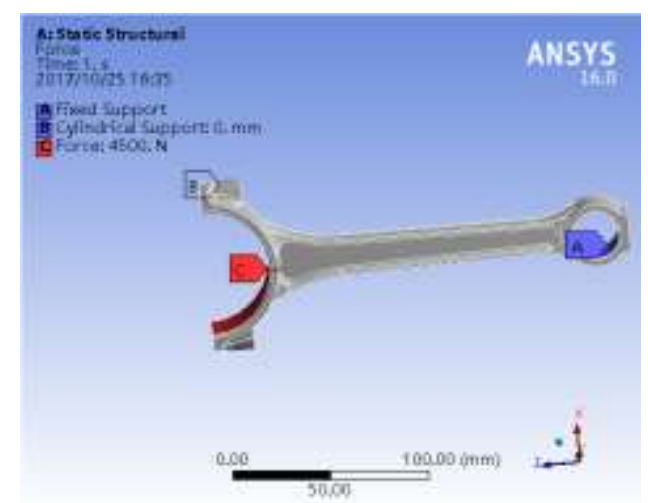

Figure 3. Finite Load and boundary conditions

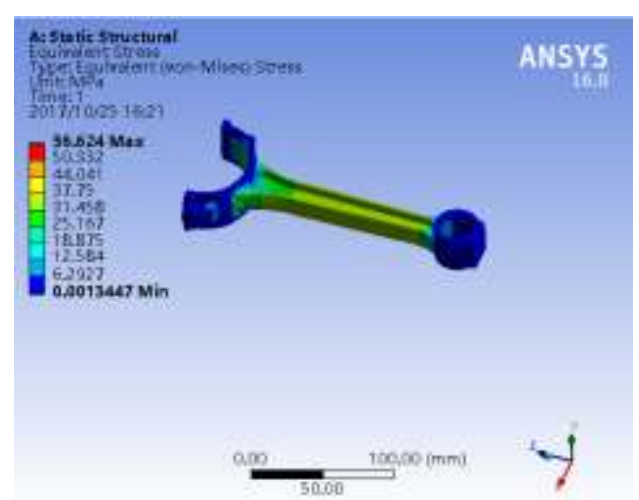

Figure 4. Finite Equivalent stress contour

Fatigue Analysis. The cause of fatigue is related to repeat loading, and fatigue usually includes two categories: high cycle fatigue and low cycle fatigue. In the actual work, the connecting rod is subjected to asymmetric cyclic stress, which is high cycle fatigue. First, the fatigue analysis tool was set up, and the fatigue strength coefficient was set to 0.8 . This coefficient can be used to modify the difference between fatigue test and computer simulation, and the other effects of the average stress can be considered [5]. The design life of the safety factor was set to $1 \mathrm{e} 6$ cycles. Because the rod is a high cycle fatigue problem, that is, there is no plastic deformation under the action of external load, so the analysis type is the stress life. Finally, the safety factor, alternating equivalent stress and fatigue sensitivity of the connecting rod are solved. The results are shown in Fig. 5 to Fig. 7.

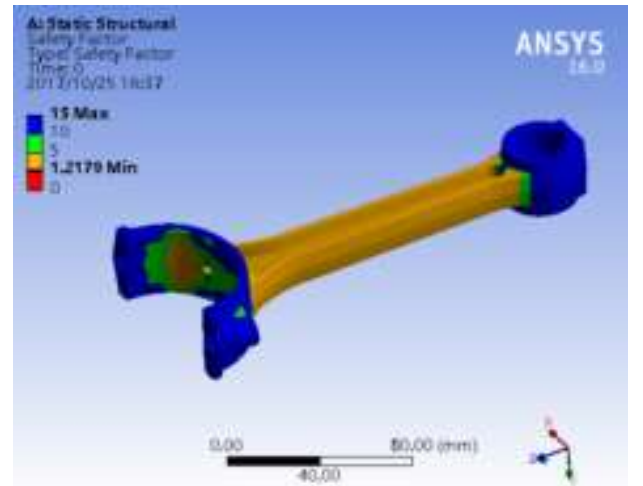

Figure 5. Finite Safety factor contour

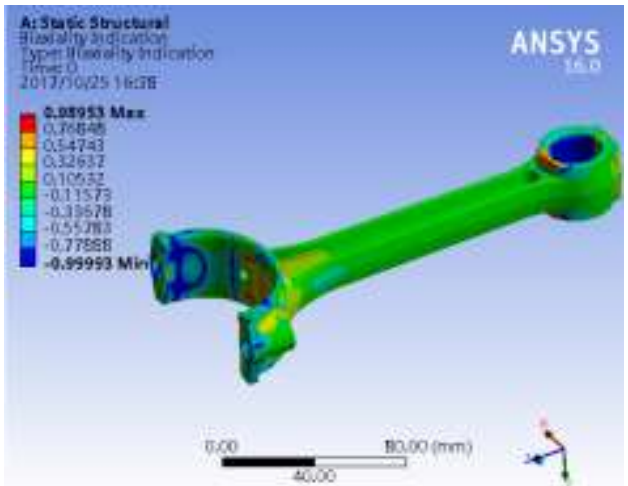

Figure 6. Finite Two axis indicator contour

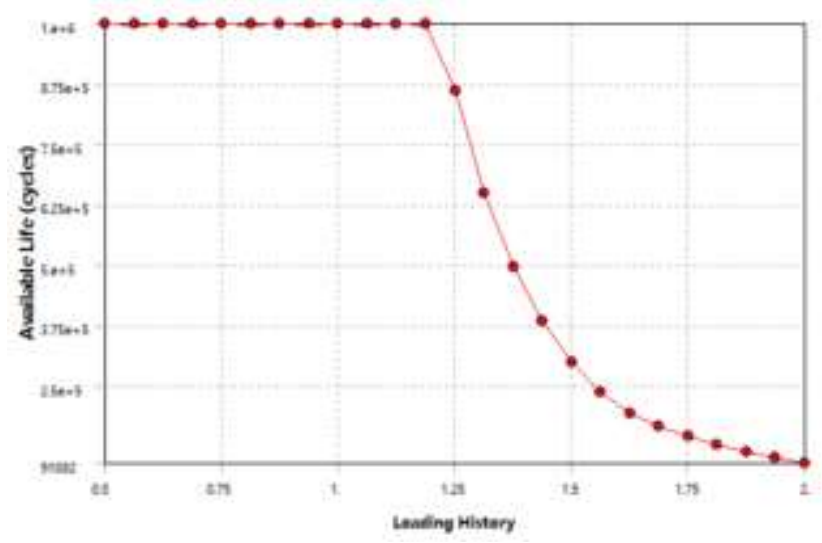

Figure 7. Finite Fatigue sensitivity of connecting rod

It can be seen from Fig. 5, the minimum safety factor of 1.2179>1, we can see that the structure is safe. It can be seen from Fig. 6 that the maximum ratio is 0.98953 and the minimum value is -0.99993 , which can be used as auxiliary to determine whether the stress state in the key area is similar to that under the experimental conditions. It can be seen from Fig. 7, about 1.24 times the 
pressure load, the fatigue life is infinite.

Re-insert the fatigue analysis tool, set the fatigue strength coefficient of 0.8 , select the process data and reduce the 0.05 times. Because the need to normalize the load history, so that the FEM load can be matched with the load history file scale factor [6]. The Goodman method is used to calculate the mean stress theory and the Signed Von Mises stress is used to compare the fatigue material data. The main reason is that Goodman's theory deals with negative and positive mean stress forms. Some points of the connecting rod are subjected to a plurality of cycles of tensile and compressive stresses, forming a crack and extending further until a critical state is reached and a fracture occurs. Fatigue damage comes from local high stress. The stochastic load - time course of the dangerous point is converted into a series of cyclic loads by rain flow counting method, and then the equivalent fatigue load is obtained.

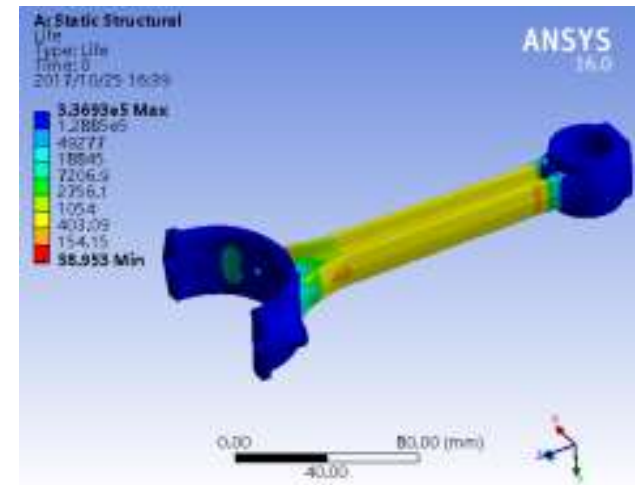

Figure 8. Finite Connecting rod life contour

It can be seen from Fig. 8 that the minimum life of the connecting rod is 58 times and the maximum life is $3.3693 \mathrm{e} 5$ times. When the number of cycles reaches the number of failures, the life is exhausted and the failure is achieved. Through the rain flow counting method, the distribution of the mean and amplitude distributions of the Rainflow matrix size is $32 \times 32$. As shown in Fig. 9, Mean in the figure represents the load cycle average after counting, Range represents the maximum value of the load cycle, and Counts represents the frequency of the load cycle. The frequency of the load cycle is 87 times, and most of the cyclic frequencies are Low average stress and low stress amplitude.

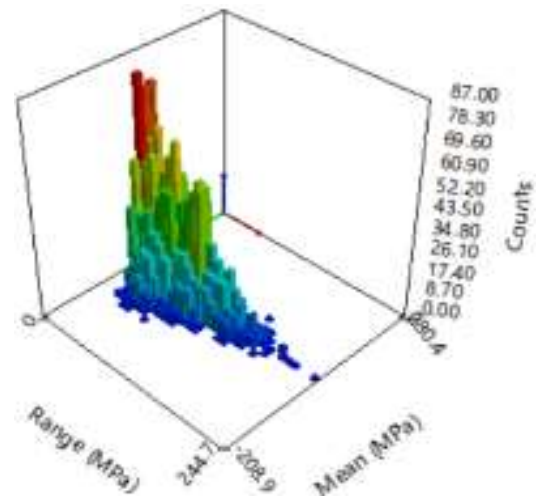

Figure 9. Finite Rainflow matrix

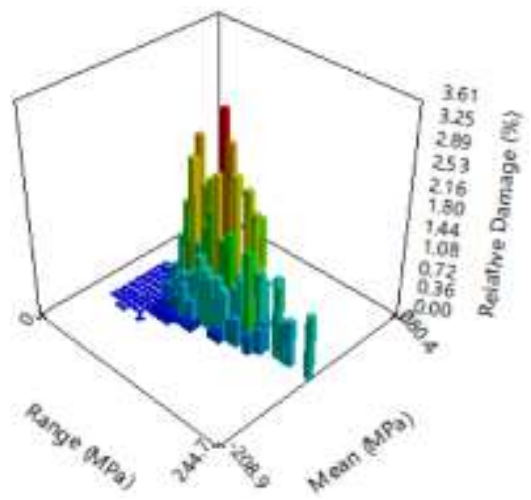

Figure 10. Finite Damage matrix

As shown in Fig. 10, the damage matrix specifies the damage to the evaluation position of the entity, and the Z-coordinate indicates the degree of relative damage, with a maximum degree of damage of 3.61. It can be seen that most of the values are for low mean stress and low stress amplitude. However, these are not caused by the greatest damage in the dangerous position, but caused by the cyclic change of the intermediate stress amplitude at the dangerous position. It reflects the damage matrix generated by the size of each bar in the display results of the designated part or surface of the critical position, thus the fatigue life and fatigue damage of mechanical 
components, can predict the life cycle of materials under cyclic loading.

\section{Conclusions}

Through the fatigue analysis theory of Ansys Workbench simulation platform, the static analysis of the engine connecting rod is first carried out, and the equivalent stress contour of the connecting rod is obtained. It is found that the strength of the connecting rod meets the requirement of use from the point of view of statics. The fatigue life of the connecting rod under different load of constant amplitude and cyclic load is analyzed. Under the constant amplitude load, the safety factor and the fatigue sensitivity of the connecting rod are mainly analyzed. Under the cyclic loading, the fatigue life and damage of the connecting rod are predicted, and the fatigue life and fatigue damage of the mechanical parts are obtained, which can predict the cycle life of the material under the alternating load. For the design and improvement of the connecting rod to provide reference and basis, shorten the development cycle, saving development costs.

\section{Acknowledgement}

The work is supported financially by the Natural Science Foundation of Hubei province under Grants (No.2016CFB581) and the research project of Hubei Education under Grants(No.Q20151103).

\section{References}

[1] Bai F., Liu F., Shi Y.H. and Liu W. Machinery Manufacturing and Automation, Vol. 46 (2017) No.1 p.124.

[2] Zhu R. F., Zhao Q. F. and Wang H. Journal of Heilongjiang Institute of Technology, Vol. 28 (2014) No. 4 p. 31

[3] Y. W., H. T. Z and Y.S. G. Journal of Mechanical Transmission, Vol. 34 (2010) No. 3, p. 68.

[4] Huang. K. and Jin. J. Machinery Design \& Manufacture, Vol. 8 (2012), p. 148.

[5] Zhao Z. X., Wang F. C. and Jing H.Q. Modular Machine Tool \& Automatic Manufacturing Technique, (2014) No. 9, p. 35. (In Chinese)

[6] Xie Y. R., Xu T. G. and Zhu J.J. JOURNAL OF DONGHUA UNIVERSITY (NATURAL SCIENCE), Vol. 41 (2015) No. 4, p. 527. 